eISSN: 2444-7986

DOI: http://dx.doi.org/10.14201/orl201671.13530

Caso clínico

\title{
TUBERCULOSIS DE OÍDO MEDIO. DESCRIPCIÓN DE DOS CASOS
}

\section{Tuberculosis of middle ear. Description of two cases}

\author{
Vania NOVOA-JUIZ*; Francisco M. PIQUERAS-PÉREZ \\ Hospital General Universitario Morales Meseguer, Murcia, España \\ *Correspondencia: vnovjui@hotmail.com
}

Fecha de recepción: 16 de noviembre de 2015

Fecha de aceptación: 22 de enero de 2016

Fecha de Publicación: 23 de enero de 2016

Conflicto de intereses: Los autores declaran no tener conflictos de intereses Imágenes: Los autores declaran haber obtenido las imágenes con el permiso de los pacientes Política de derechos y autoarchivo: se permite el autoarchivo de la versión post-print (SHERPA/RoMEO) Licencia CC BY-NC-ND. Licencia Creative Commons Atribución-NoComercial-SinDerivar 4.0 Internacional (c) Universidad de Salamanca. Su comercialización está sujeta al permiso del editor

RESUMEN Introducción: El aumento de incidencia de la tuberculosis en los países desarrollados conlle-
va un incremento del porcentaje de pacientes con presentaciones y localizaciones atípicas,
entre ellas la tuberculosis de oído medio, afección que habitualmente no se considera ante
una patología del oído. Objetivo: Concienciar a los profesionales de la posibilidad de una
tuberculosis ótica y facilitar su manejo clínico. Descripción: Revisamos la literatura sobre
tuberculosis de oído medio y presentamos dos casos clínicos. Resultados: La tuberculosis
del oído medio es una enfermedad muy rara, multiforme, caracterizada por el dolor de oído,
la otorrea y la presencia de tejido de granulación, cuyo diagnóstico, habitualmente tardío
debido al bajo índice de sospecha, se basa en estudios anatomopatológicos y microbiológi-
cos. Presentamos dos casos clínicos ilustrativos de la evolución y manejo de la enfermedad.
Conclusiones: Las otitis medias crónicas de sintomatología y/o presentación atípicas, espe-
cialmente por la existencia de dolor crónico y de tejido de granulación exuberante y/o recu-
rente, deberían conllevar la toma de muestras para estudios histopatológicos y/o microbio-
lógicos que orienten hacia este diagnóstico.

PALABRAS CLAVE otitis media; tuberculosis; diagnóstico

SUMMARY

Introduction and objective : The increasing incidence of tuberculosis in developed countries leads to an increase in the percentage of patients with atypical presentations and locations, including tuberculosis of the middle ear, a condition that is usually not considered before an ear pathology. Objective: Raising awareness among professionals about the possibility of an otic tuberculosis and facilitate its clinical management. Description: The literature on tuberculosis of the middle ear was revised and two cases were reported. Results : Tuberculosis of the middle ear is a very rare and multiform disease, characterized by ear pain , otorrhea and the presence of granulation tissue, whose diagnosis, that is usually late due to the low index of suspicion, is based on pathological and microbiological studies. We present two illustrative case studies of evolution and management of the disease. Conclusions: Chronic otitis media 
with symptomatology and/or atypical presentation, especially by the existence of chronic pain and lush and/or recurrent granulation tissue, should involve taking samples for histopathological and/or microbiological studies that may lead to this diagnosis.

\section{INTRODUCCIÓN}

La tendencia al descenso de la incidencia de la tuberculosis en los países desarrollados se ha interrumpido durante as últimas décadas por la migración de poblaciones procedentes de áreas endémicas, la existencia de focos de pobreza en las grandes ciudades, el incremento de población inmunodeprimida por tratamiento con inmunosupresores, la presencia del SIDA y la aparición de cepas resistentes [1].

La tuberculosis puede afectar a cualquier órgano, aunque su asiento preferencial es el pulmón. Sólo del 15 al $30 \%$ de los casos de tuberculosis en la población general son extrapulmonares, si bien esta proporción puede alcanzar del 50 al $80 \%$ de los casos en paciente inmunodeprimidos [2].

En el territorio ORL la manifestación más frecuente es la linfadenitis cervical, que representa el 95\& de los casos, mientras que localizaciones como la laringe, faringe, oído, fosas nasales, senos paranasales, cávum o glándulas salivales son extremadamente raras [1]. La afectación del oído es una forma excepcional de tuberculosis $[1,2]$ y habitualmente no se considera esta etiología, lo que implica una demora en su diagnóstico, aplicar tratamientos que están abocados al fracaso y lo la progresión de la enfermedad.

El objetivo de este trabajo es concienciar a los profesionales de la medicina, particularmente de la Otorrinolaringología, de la posibilidad de una tuberculosis ótica y a facilitar su manejo clínico.

\section{DESCRIPCIÓN}

Primer caso.

Mujer de 35 años, de nacionalidad rusa, con antecedentes de migraña y epilepsia generalizada, que consultó de urgencia por dolor de oído izquierdo (OI) y cefalea ipsilateral, que se acompañaba de vómitos desde 4 días antes sin mejoría con analgésicos y antibióticos. En los 2 años previos había acudido en repetidas ocasiones a su centro de salud por dolor episódico de OI. La TC craneal puso de relieve una ocupación del canal auditivo ex- terno (CAE) izquierdo y de las celdillas mastoideas ipsilaterales, por material de densidad partes blandas o secreciones, sin signos de complicaciones intracraneales. Derivada a ORL, la exploración física era poco demostrativa debido a que la otoscopia le resultaba a la paciente muy dolorosa, pareciendo que la membrana timpánica (MT) estaba íntegra, engrosada, muy vascularizada y con pérdida de referencias habituales. En la audiometría tonal se objetivaba una hipoacusia de transmisión de $60 \mathrm{~dB}$ en OI. Se inició tratamiento con antibióticos orales y tópicos con diagnóstico de presunción de otitis media y externa de etiología bacteriana. La paciente empeoró en las semanas siguientes a pesar del tratamiento con intensificación de su otalgia y cefalea habitual, con hipoestesia de la hemicara izquierda, lo que motivó su ingreso. Se realizó una TC y una RM de oídos que evidenció otomastoiditis izquierda con ocupación del oído medio y mastoides izquierda por material de consistencia partes blandas (Figura 1).

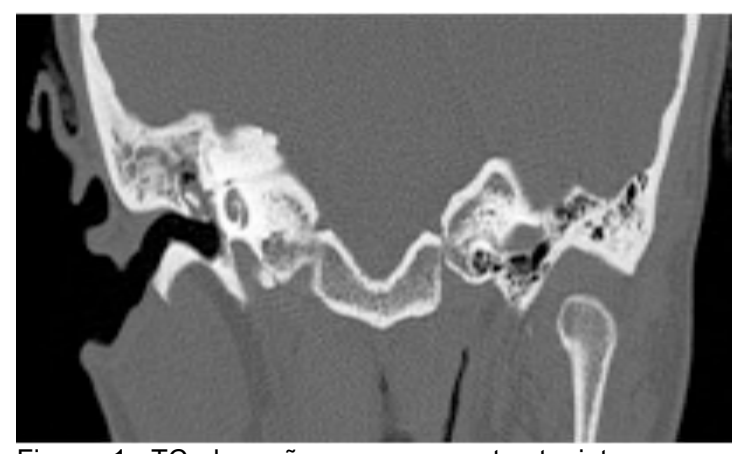

Figura 1. TC de peñascos con contraste intravenoso. Corte coronal. Otomastoiditis izquierda con ocupación de oído medio y mastoides izquierda.

Se decidió intervenir quirúrgicamente, objetivando durante la cirugía un tejido de granulación muy exuberante en las cavidades del oído medio del que se enviaron muestras a Anatomía Patológica (AP). Se realizó una mastoidectomía y timpanoplastia tipo III. El resultado histopatológico resultó compatible 
con granulomatosis necrotizante sugestiva de tuberculosis (Figura 2). Se realizó Mantoux que resultó positivo. Se realizó una serología completa que descartó otras infecciones como el VIH.

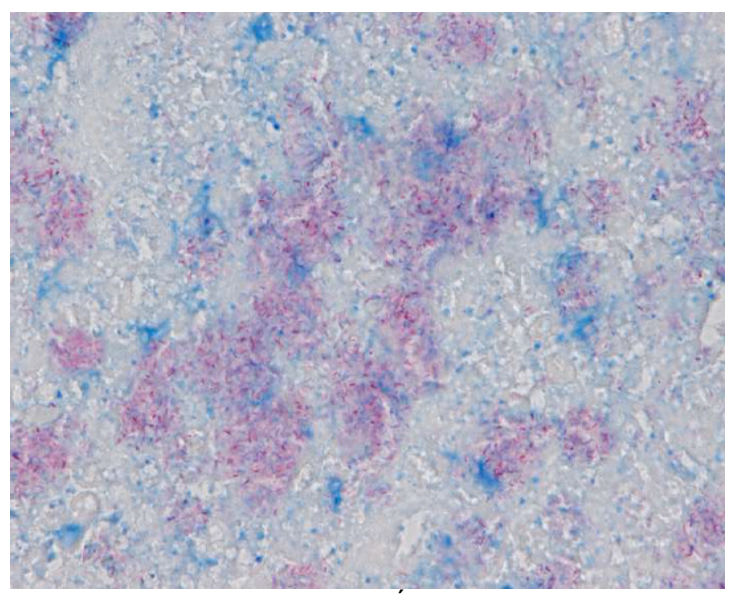

Figura 2. Imagen de microscopla de muestra obtenida de caja del tímpano. Granulomatosis necrotizante sugestiva de tuberculosis.

Se inició pauta de tratamiento tuberculostático con rifampicina, isoniazida, pirazinamida y etambutol. Coincidiendo con el inicio del tratamiento presentó fiebre alta y derrame pleural sugestivo de tuberculosis (Figura 3). La paciente, dos años después, evoluciona favorablemente resolviéndose la enfermedad pulmonar y del oído. Como consecuencia de la enfermedad presenta una hipoacusia permanente y requiere audífono en ese oído.

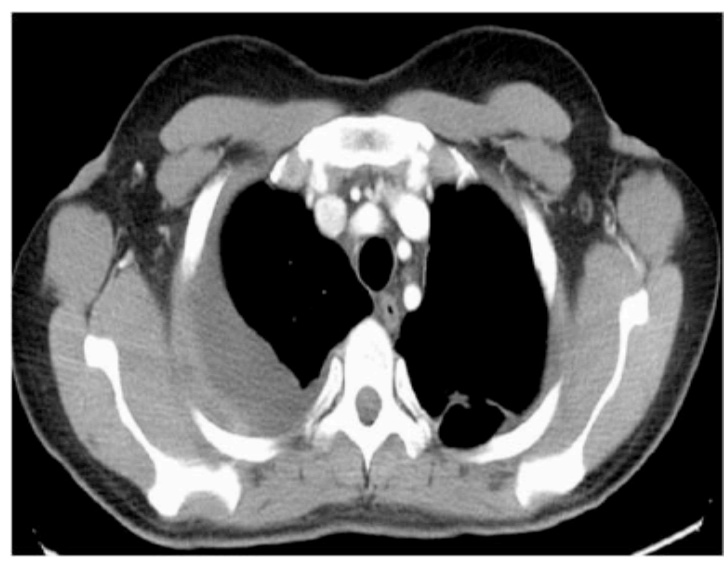

Figura 3. TC de tórax. Corte axial. Derrame pleural derecho que ocupa $2 / 3$ de hemitórax derecho con importante realce y engrosamiento liso de la superficie pleural parietal.
Segundo caso.

Mujer de 41 años, de nacionalidad española, sin antecedentes de interés, que consultó por otalgia y otorrea de oído derecho (OD) de varios meses de evolución. En la otoscopia destacaba una formación polipoidea sobre la "pars fláccida" de la MT. Se recomendó tratamiento con gentamicina y dexametasona en solución tópica. Revisada 10 días después, se objetivó ligero exudado y retracción de la MT del OD y exudado cremoso blanquecino sobre la MT del OI, previamente normal. Se instauró tratamiento tópico bilateral con alcohol boricado y 1 mes después se constató perforación subtotal de ambas MT (Figura 4), con pérdida de las referencias habituales y gran tofo de esclerosis en cajas timpánicas.

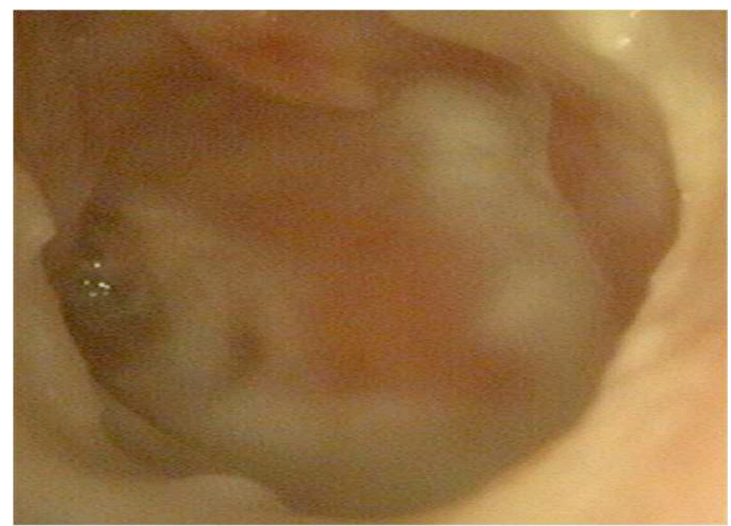

Figura 4. Fotografía del oído. Perforación subtotal de membrana timpánica con restos de granulación y otorrea.

La audiometría tonal liminar mostraba hipoacusia de transmisión bilateral de $50 \mathrm{~dB}$ con caída en agudos. Con el diagnóstico de otitis media crónica bilateral se planteó la posibilidad de timpanoplastia o audífonos. La paciente optó por audífonos. Consultó 5 meses después por episodios recurrentes de otorrea bilateral. En la otomicroscopía destacaba exudado amarillento con mucosa de oído medio de aspecto granulomatoso. Se extirpó parte del tejido de granulación, que histológicamente fue informado como otitis crónica granulomatosa con células gigantes de Langhans, necrosis caseosa y abundantes bacilos ácido-alcohol resistentes (Figura 5), sugestiva de etiología tuberculosa. En la radiografía de tórax no había datos de enfermedad pulmonar y la TC de peñasco mostraba una ocupación bilateral de oídos medios 
y mastoides, sin clara afectación ósea (Figura 6).

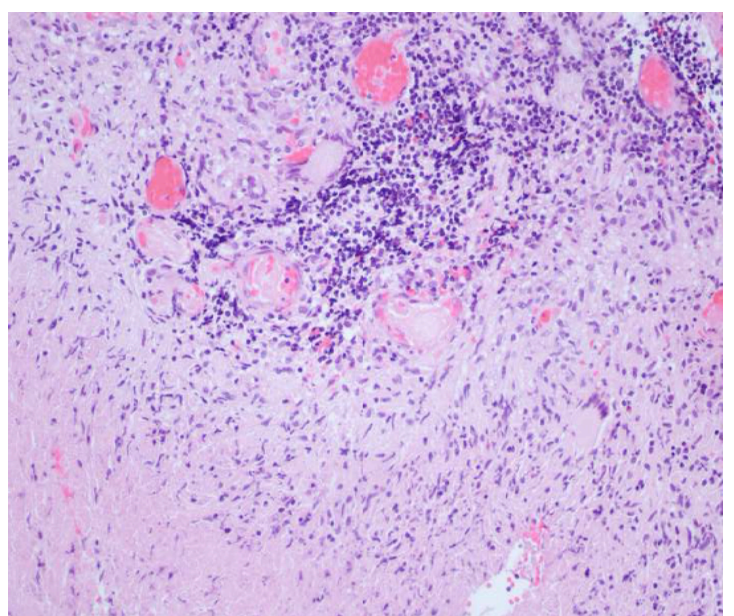

Figura 5. Imagen de microscopía de muestra de oído. Necrosis caseosa en la esquina inferior izquierda delimitada por "histiocitos en empalizada" y agregados granulomatosos con células gigantes tipo Langhans.

La serología de la paciente no revelaba otro tipo de infecciones o inmunosupresión. El test de Mantoux resultó positivo. Se inició tratamiento antituberculoso, debido al alto índice de sospecha de la enfermedad, a la espera del resultado del cultivo, en el que finalmente se aisló M. Tuberculosis complex. La paciente tras finalizar el tratamiento sufre secuelas de la infección, ya curada, en ambos oídos, que son la pérdida de audición y la perforación de ambas MT.

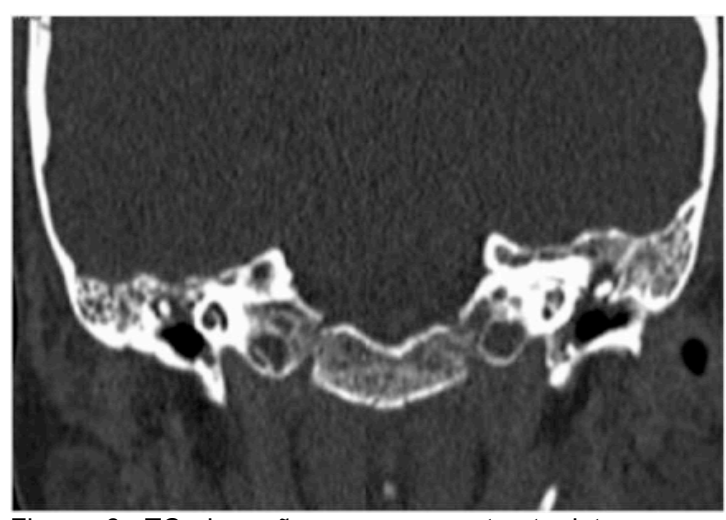

Figura 6. TC de peñascos con contraste intravenoso. Corte coronal. Ocupación bilateral de oídos medios y mastoides, sin clara afectación ósea.

\section{DISCUSIÓN}

La tuberculosis del hueso temporal fue descrita por primera vez por Jean Louis Petit en el siglo XVIII y los signos clínicos de la enfermedad fueron recogidos por Wilde en 1853. Koch demostró la existencia de Mycobacterium tuberculosis en 1882 y Esche aisló al germen en las secreciones de oído medio en 1883 [3].

Se estima que más de 2.000 millones de personas en el mundo (cerca de un tercio de la población mundial) presentan infección por Mycobacterium tuberculosis. Según la OMS, en 2012, 8,6 millones de personas enfermaron de tuberculosis y 1,4 millones murieron por esta causa. La epidemiología de la tuberculosis varía según la región del mundo de la que hablemos. Las mayores prevalencias (100/100.000 o mayor) se registran en África Subsahariana, India e islas del Sudeste asiático y Micronesia. Las prevalencias intermedias (26 a 100/100.000 casos) se dan en China, América Central y del Sur, Europa del Este, y Norte de África. Las prevalencias son bajas (menor de 25 casos) en USA, Europa Occidental, Canadá, Japón y Australia. La pobreza, el VIH, y las resistencias a los fármacos antituberculosos son los factores más importantes en el resurgimiento global de la tuberculosis como epidemia. Aproximadamente un $95 \%$ de los casos suceden en países en vías de desarrollo. Uno de cada 14 nuevos casos ocurren en individuos infectados por VIH, el 85\% de ellos en África [4].

Desde el punto de vista anatomoclínico se identifican 3 tipos de tuberculosis: miliar, granulomatosa y caseosa. El tipo miliar se asocia con infección superficial, el granulomatoso con afectación superficial del hueso y el caseoso con necrosis masiva y secuestros óseos [3].

La tuberculosis del oído medio (TOM) es rara, puede ocurrir a cualquier edad y sus hallazgos clínicos son similares a otros formas de otitis media crónica (OMC) [5].

Respecto a las posibles vías de contaminación y a la patogénesis de la TOM se distinguen $[6,7]$ :

1. TOM primaria, en la que en ausencia de otro foco tuberculoso demostrado se supone que el bacilo alcanzó el oído por implantación directa en el CAE a través de la trompa de Eustaquio.

2. TOM secundaria, con transmisión de M. tuberculosis por vía hematógena o tubá- 
rica desde un foco a distancia, lo más frecuentemente pulmonar.

Clásicamente la TOM es una afección unilateral vinculada a la tríada clínica otorrea no dolorosa, perforación timpánica múltiple, y parálisis facial, y asociada a la formación de tejido de granulación y necrosis ósea. (Wallmer, 1953) [3]. Esta presentación es excepcional hoy en día [7], ya que la parálisis facial sólo se da en aproximadamente el $16 \%$ de los adultos y el $35 \%$ de los niños [8].

En las fases iniciales suele existir otorrea crónica no dolorosa de meses de evolución e hipoacusia. La otoscopia generalmente revela exudado, una perforación de la MT y tejido de granulación. El estudio auditivo objetiva una hipoacusia de intensidad variable, que suele ser de transmisión, ocasionalmente mixta o neurosensorial [6], con frecuencia de instauración aguda y de intensidad desproporcionada con las lesiones objetivables [7].

La falta de especificidad de estos síntomas, comunes a otras formas de OMC, junto a un bajo índice de sospecha de la enfermedad, provoca habitualmente un retraso en su diagnóstico y en la instauración del tratamiento específico [6]

En presencia de una otorrea de evolución tórpida se debe considerar la posibilidad de tuberculosis ante el fracaso de medidas terapéuticas habituales y/o presencia de hallazgos o complicaciones inusuales (tejido de granulación exuberante recurrente, parálisis facial en el contexto de una OMC no colesteatomatosa), especialmente si hay antecedentes de contagio en el entorno cercano, de enfermedad tuberculosa en el paciente o de factores de riesgo (zona geográfica, inmunodepresión, contexto social) [2,7].

Con las técnicas de imagen [6] especialmente con la TC de peñasco, podemos encontrar ocupación por material de densidad partes blandas en las celdas mastoideas, que engloban la cadena osicular y ocasionalmente erosión ósea. Ambos hallazgos son inespecíficos y pueden aparecer en otra formas de OMC. El diagnóstico de sospecha se basa en el estudio histopatológico del tejido de granulación que habitualmente acompaña a esta afección, constatando la existencia de lesiones sugestivas de tuberculosis (células epitelioides, células multinucleadas gigantes de Langhans y necrosis caseosa, etc.) y la presencia de bacilos ácido alcohol resistentes con la tinción de Ziehl-Neelsen [9, 10, 11].
El diagnóstico de certeza se alcanza con la identificación del bacilo mediante el estudio bacteriológico de las muestras biológicas obtenidas, habitualmente tejido de granulación o exudados, y su identificación mediante técnicas de PCR [12] y su cultivo en medio Lowenstein [5, 13].

Hasta en un $79 \%$ de los pacientes, la identificación del bacilo con tinciones no es posible y los cultivos son negativos [3].

Ante una TOM es obligado investigar la posibilidad de que existan otros focos tuberculosos realizando al menos una radiografía de tórax, aunque en un $40-50 \%$ de los pacientes afectos de TOM no se encuentra enfermedad en otras localizaciones [6, 7].

El tratamiento de la otitis tuberculosa es médico, con la asociación de isoniazida, rifampicina, pirazinamida y etambutol con pautas de 6 a 9 meses.

La TOM no tratada puede conducir a secuelas severas y permanentes como hipoacusia, parálisis facial periférica, fístulas laberínticas, laberintitis, osteomielitis y diseminación de infección al SNC [5]. La cirugía sólo tiene interés en la obtención de muestras que posibiliten el diagnóstico inicial, en caso de complicaciones (secuestros óseos o abscesos) y para el tratamiento de las secuelas (hipoacusia, perforación timpánica, parálisis facial, etc.) $[3,5-7,14]$.

La TOM es tan inusual en los países desarrollados y su sintomatología tan inespecífica que ante una patología infecciosa de oído raramente se considera esta etiología. Este bajo grado de sospecha conduce a que el diagnóstico acostumbre a ser tardío. Este retraso y la demora de un tratamiento correcto conlleva la progresión de la enfermedad y la posibilidad de secuelas y complicaciones, prolongando el sufrimiento del paciente $y$ ocasionando la frustración del médico además del incremento en los costes.

Es de suponer que con el aumento de la incidencia de la tuberculosis en los países desarrollados se incremente también la existencia de otitis tuberculosa, así que debemos estar prevenidos, considerar esta eventualidad y conocer su manejo.

Una de las pacientes procedía de Europa del Este, en donde la prevalencia de la enfermedad es mayor que en nuestro medio, ilustrando la relevancia de los flujos migratorios sobre la incidencia de la tuberculosis. 
En relación a la puerta de entrada y el desarrollo de la enfermedad, el primero de nuestros casos encajaría con una TOM secundaria, ya que la enfermedad de oído coexistía con una tuberculosis pulmonar. El segundo caso parece corresponder a una TOM bilateral primaria con posible puerta de entrada a través de la trompa de Eustaquio.

El tiempo entre la primera consulta y el diagnóstico fue en el primer caso de 2 años y en el segundo de 6 meses, lo que confirma la naturaleza crónica y la demora habitual en el diagnóstico.

Si bien lo más habitualmente descrito en la Literatura es la TOM unilateral, a infección bilateral también es posible como ilustra nuestro segundo caso.

En ambas pacientes destaca la presencia de dolor de oído, especialmente en la primera, síntoma generalmente ausente o ligero y pasando a segundo plano tras la otorrea en OMC.

La OMC de sintomatología y/o presentación atípicas junto con la presencia de dolor crónico y de tejido de granulación exuberante y recurrente debería indicar la toma de muestra para estudio histopatológico y/o microbiológico que orienten al diagnóstico.

En nuestros dos casos la clave del diagnóstico resultó ser el estudio histopatológico del tejido de granulación que proliferaba en el oído medio. La evidencia de granulomas con células epitelioides, células multinucledas gigantes de Langhans, necrosis caseosa y bacilos ácido alcohol resistentes es muy sugestiva de TOM. Este estudio resulta también determinante para establecer el diagnóstico diferencial con otras infecciones crónicas, colesteatoma, otitis externa maligna, carcinoma epidermoide de oído medio, etc.

Los estudios microbiológicos (visualización directa del germen en el espécimen, cultivo, $\mathrm{PCR}$ ) tiene especial interés para confirmar el diagnóstico.

Sin embargo con frecuencia la confirmación diagnóstica puede resultar frustrada por imposibilidad de visualizar o identificar al bacilo debido a su baja tasa, tratamientos previos, la existencia de gérmenes oportunistas, infecciones secundarias o técnicas de visualización y/o cultivo inapropiadas. En la Literatura se cuantifica este hecho en hasta un $79 \%$ de los pacientes [3].
Si a pesar de esta eventualidad tenemos un alto índice de sospecha histopatológico debemos repetir los estudios que resultaron inicialmente negativos [3], e incluso estaría indicado el inicio del tratamiento antituberculosos de modo empírico si resulta positiva la prueba de Mantoux o PPD y el estudio histopatológico es sugestivo de la enfermedad [15].

\section{CONCLUSIONES}

La TOM es una afección rara en los países desarrollados, pero es posible que el repunte de la incidencia de tuberculosis derive en un aumento de casos de otitis tuberculosa, lo que exige cierto grado de alerta por los profesionales de la ORL.

Los síntomas y signos inespecíficos de la otitis media tuberculosa y el bajo índice de sospecha provoca un retraso diagnóstico y la progresión de la enfermedad.

La OMC de sintomatología y/o presentación atípicas, especialmente dolor crónico y tejido de granulación exuberante y recurrente indica la toma de muestras para estudios histopatológicos y/o microbiológicos que orienten al diagnóstico.

\section{AGRADECIMIENTOS:}

A los Servicios de Microbiología, Medicina Infecciosa y Anatomía Patológica del Hospital Morales Meseguer por su contribución.

\section{BIBLIOGRAFÍA}

1. Galo Peralta Fernández. Tuberculosis de cabeza y cuello. Acta Otorrinolaringol Esp. 2009;60(1):59-66.

2. Lahoz Zamarro MT, Fernández Alamán A, Ortiz Domínguez L, Mirallas Mezquita M. Tuberculosis de cabeza y cuello: nuestra experiencia. O.R.L. ARAGON, 2013;16(1):13-6.

3. Aremu SK, Alabi BS. Tuberculous otitis media: a case presentation and review of the literature. BMJ Case Rep. 2010 Dec 1;2010. pii: bcr0220102721. doi: 10.1136/bcr.02.2010.2721. 
4. Horsburgh CR. Epidemiology of tuberculosis. UpToDate, Literature review current through: Dec 2015. This topic last updated: Oct 1, 2015. Disponible en:

http://www.uptodate.com/contents/epid emiology-of-tuberculosis. [Citado el: 2201-2016]

5. Dale OT, Clarke AR, Drysdale AJ. Challenges encountered in the diagnosis of tuberculous otitis media: case report and literature review. J Laryngol Otol. 2011;125(7):738-40.

6. González Pena M, Blanc JM, Pardo J. Otorrea como primera manifestación de tuberculosis. Med Clin (Barc). 2011;12;136(6):268-9.

7. Chirch LM, Ahmad K, Spinner W, Jimenez VE, Donelan SV, Smouha E. Tuberculous otitis media: report of 2 cases on Long Island, N.Y., and a review of all cases reported in the United States from 1990 through 2003. Ear Nose Throat J. 2005;84(8):488,490,492 passim. Review.

8. Varty S, Vaidya D, Parasram K, Prabhat D, Joshi S. Tuberculous otitis media-are we missing it? Indian J Otolaryngol Head Neck Surg. 2000;52(2):143-6.

9. Vaamonde P, Castro C, García-Soto N, Labella T, Lozano A. Tuberculous otitismedia: a significant diagnostic challenge. Otolaryngol Head Neck Surg. 2004;130(6):759-66.
10. Linthicum Jr FH. Tuberculous otitis media. Otol Neurotol. 2002;23(2):235-6.

11. Adhikari P. Tuberculous otitis media: a review of literature. The Internet J Otorhinolaryngol 2009;9(1):7.

12. Cho YS, Lee HS, Kim SW, Chung KH, Lee DK, Koh WJ, Kim MG. Tuberculous otitis media: a clinical and radiologic analysis of 52 patients. Laryngoscope. 2006;116(6):921-7.

13. Aupy B, Jahidi A, Benariba F, Akre A, Ettien D, Saint-Blancard P, Kossowski P. Tuberculosis del oído medio. EMC Otorrinolaringología 2009;38(2):1-6.

14. Di Rienzo L, Tirelli GC, D'Ottavi LR, Cerqua N. [Primary tuberculosis of the middle ear: description of 2 cases and review of the literature]. Acta Otorhinolaryngol Ital. 2001;21(6):365-70.

15. Pai M, Menzies D. Diagnosis of latent tuberculosis infection (tuberculosis screening) in HIV negative adults. UpToDate Literature review current through: Dec 2014, this topic last updated: Jul 31, 2014. Disponible en: http://www.uptodate.com/contents/diag nosis-of-latent-tuberculosis-infection-inhiv-infected-patients. [Citado el: 22-01-2016]. 